\title{
Designing for Reflection on Sender Effort in Close Personal Communication
}

\author{
Ryan Kelly \\ University of Melbourne \\ Melbourne, Australia \\ ryan.kelly@unimelb.edu.au
}

\author{
Daniel Gooch \\ The Open University \\ Milton Keynes, United Kingdom \\ daniel.gooch@open.ac.uk
}

\author{
Leon Watts \\ University of Bath \\ Bath, United Kindom \\ l.watts@bath.ac.uk
}

\begin{abstract}
Research has identified that people in close relationships value effort that is invested into the creation of digital messages. This paper explores the potential for communication systems to encourage reflection by revealing evidence of effort to message recipients, allowing for it to be appreciated. Focusing on text-based communication, we report findings from an exploratory study of three interface prototypes that probe users' reactions to the notion of revealing sender effort. We find that information about effort can foster empathy and appreciation by encouraging reflection over meaningful actions. However, designers of communication tools must address the issues of authenticity, controlled disclosure and cost in access if reflection on effort is to be valued. We consider how designers might negotiate these issues in future effortsensitive communication technologies.
\end{abstract}

\section{CCS CONCEPTS}

- Human-centered computing $\rightarrow$ Empirical studies in interaction design;

\section{KEYWORDS}

Close Relationships, Communication, Effort, Reflection

\section{ACM Reference Format:}

Ryan Kelly, Daniel Gooch, and Leon Watts. 2018. Designing for Reflection on Sender Effort in Close Personal Communication. In Proceedings of the 30th Australian Computer-Human Interaction Conference (OzCHI '18), December 4-7, 2018, Melbourne, VIC, Australia. ACM, New York, NY, USA, 12 pages. https://doi.org/10.1145/3292147. 3292174

Permission to make digital or hard copies of all or part of this work for personal or classroom use is granted without fee provided that copies are not made or distributed for profit or commercial advantage and that copies bear this notice and the full citation on the first page. Copyrights for components of this work owned by others than the author(s) must be honored. Abstracting with credit is permitted. To copy otherwise, or republish, to post on servers or to redistribute to lists, requires prior specific permission and/or a fee. Request permissions from permissions@acm.org. OzCHI '18, December 4-7, 2018, Melbourne, VIC, Australia

(c) 2018 Copyright held by the owner/author(s). Publication rights licensed to ACM.

ACM ISBN 978-1-4503-6188-0/18/12 ..\$15.00

https://doi.org/10.1145/3292147.3292174

\section{INTRODUCTION}

Digital communication technologies such as email, instant messaging (IM) and SMS are routinely used to mediate close personal relationships. For many people, these systems have considerable value because they allow relationships to be maintained quickly and with ease [23]. IM applications can, for example, make it easy to coordinate social gatherings [46] and can allow people to acquire a sense of 'dwelling' that may be difficult to achieve offline [34]. Similarly, systems that enable phatic communication can support feelings of presence-in-absence through the exchange of abstract media [2, 22, 38], e.g. Facebook 'pokes' [49] or randomly chosen emoji [25]. These kinds of communication are usually very easy to produce and yet provide a high ceiling for supporting intimacy within close personal relationships [44, 48].

In addition to mediating lightweight exchanges, HCI research has recently drawn attention to the potential for communication systems to demand effort from the persons involved [e.g. 15, 28, 37, 39]. This is based on the fact that people recognise the value of effort when communicating with close relational partners [24] and because people value systems which make their effort clear to message recipients [28]. Other work suggests that effort in communication can stimulate feelings of mutual affection and care [30,33], and that receiving high-effort messages can contribute positively to well-being [8]. These findings provide reason to believe that communication technologies which encourage the investment of meaningful effort-and which make this effort clear to a recipient-can act as positive contributors to relational maintenance [23, 24, 27].

However, research suggests that it can sometimes be difficult to appreciate effort in digital communication. This is because effort that is invested into the creation of a message may not be clear to the recipient [24, 37]. Actions such as the mindful composition of text [32] or choices of expressive media $[11,25]$ may give powerful evidence of effortful relationship maintenance, and yet may not be apparent when messages are received [37]. This presents an opportunity to consider how a messaging system might be designed so as to convey such effort to recipients, and to explore how this might encourage reflection in close relationships [23, 24]. At the same time, there is a need to consider how such a design 
might shape interpersonal exchanges in new and unexpected ways [1]. Effort has the potential to be resented or valued, and information about effort could easily be regarded as interesting or mundane. These issues are important because they will determine whether reflection on effort has utility for close relationships, and whether this is an avenue worth pursuing in the design of communication technologies.

The present research explores these issues through a study of users' reactions to the notion of revealing effort in textbased communication. We adopt a research through design orientation [52] in which potential users are exposed to a set of speculative design prompts as a way of eliciting feedback about the problem of interest [17]. Each prompt is envisaged as a feasible augmentation to a text-based messaging system, and represents a different approach to capturing a sender's effort and revealing it to a recipient. The study allow us to explore the value that users might gain through reflecting on a partner's effort, and provides advance insight into issues that can affect its acceptance. Our study makes three contributions to the literature on effortful communication technologies [23, 24]:

- A design-oriented exploration of the means by which sender effort can be revealed.

- Insight into users' reactions to interfaces that encourage reflection about sender effort.

- New knowledge of issues for designers to consider when creating interfaces that aim to reveal effort in communication technologies.

\section{BACKGROUND}

This section grounds our design work in an understanding of effort and its value to relational communication. We then consider the means by which effort can be revealed in the design of messaging applications.

\section{The Value of Effort in Relational Technologies}

Effort is a term that is familiar to HCI and yet previous research indicates that it has no agreed definition [24]. An early characterisation by Zijlstra positions effort in terms of the work required to handle a task [51]. The received wisdom is that any task involves an amount of workload, and this workload places demand on the capacities of its performer. Effort describes the work that is done to alleviate this demand [51]. This perspective has informed task-centric approaches to interaction design in which effort is seen as something to be minimised [e.g. 19].

In the context of close relationships, effort has been aligned with the notion of relational maintenance [24, 42], which refers to "efforts to keep a relationship in a specified state or condition" [12, p. 164]. Such effort can be witnessed in strategic exchanges of birthday gifts [10] and in routine activities such as spending time together or chatting online [40]. These behaviours represent the kinds of effort that are central to feelings of closeness, and thus would rarely be positioned as something that should be minimised.

This function of effort in close relationships has been acknowledged in the HCI literature on communication technologies [15]. Qualitative investigations have identified that the investment of time and effort into messaging is highly meaningful to people and is seen as reflecting a person's commitment to the exchange [27, 28, 37]. Similar evidence has emerged from field studies of messaging technologies (e.g. $[13,16])$ and from the CSCW literature on relational maintenance in social media $[7,8,30]$. According to these studies, decisions to send particular types of messages are equated with investment in a relationship on the basis of effort and care. For example, using low cost 'likes' on Facebook is seen as expressing less affection than private messages because messages require greater effort to compose [42].

More recent work has explored how communication technologies can be designed to stimulate effort in conversation. For example, Kelly et al. presented Message Builder, a system that displayed a character count for each message as a way of encouraging reflection over effort [23]. Their study found that Message Builder supported effortful conversations that became increasingly deep and meaningful over time. However, some of their participants reported difficulty in recognising effort in Message Builder, primarily due to the limited scope of the character count as a proxy for meaningful action [23]. We build on this work by considering alternative ways of encouraging reflection about effort in messaging, and derive an initial understanding of how and when such effort is likely to be appreciated.

\section{Revealing Effort for Reflection and Appreciation}

Previous work suggests that encouraging reflection between close partners can support rich meaning-making and deep interpersonal sharing [5]. Here, reflection refers to the act of reviewing information to make sense of it, come to a better understanding, or gain insight [3]. In a close relationship, this can refer to thinking about a partner's actions and what these actions mean, as evidenced by digital traces that provide a shared history [43]. Previous work has explored the potential for digital artefacts to encourage reflective thought in close relationships [5, 43, 45] but has not explored designs for reflecting on effort as a contribution to caring practices.

The idea of designing to encourage reflection over effort raises the question of how one might reveal a sender's effort to the recipient of a message. This in turn requires consideration of what form this effort might take, and whether or not certain kinds of effort might be more or less valued by message recipients. A starting point for this discussion is the work of Markopoulos [31], who identified two kinds of effort 
that can arise in communication systems. First, procedural effort is that which is required to make use of a system, e.g. turning on a device or pressing buttons. Markopoulos argues that this kind of effort is mundane and is not valuable to people. In contrast, personal effort is that which is expended in service of the message recipient, e.g. in the selection of media or in choosing words that the recipient will find engaging.

From the perspective of revealing effort, this distinction might suggest a need to inform people about personal (rather than procedural) effort as a way of fostering reflection and appreciation. In practice, however, personal effort is likely to be coupled with procedural effort. This is because the operations carried out by a message sender can evince personal investment, particularly when those operations are recognised as difficult to perform [24]. Thus, insight into procedural effort, in the form of operations carried out during composition, may be a necessary precursor to reflecting on personal effort in communication.

A different conceptualisation of effort was presented by Kelly et al. [24], who identified five qualities of meaningful effort that arise across a range of communication experiences. These qualities include discretionary investment, personal craft, and dedicated time [24]. Kelly et al. proposed several ideas for supporting recognition of these practices (e.g. a video replay) but did not study whether these ideas would be acceptable to people in practice. Our study extends their work by probing the space of plausible possibilities for revealing effort, with a view to understanding how meaningful effort might (or might not) be recognised by the users of a messaging system.

It is worth noting that some features of existing communication tools may permit reflection over sender effort. Popular apps like Facebook Messenger and Whatsapp provide status cues to indicate that a person is composing a message, e.g. by displaying the words "Ryan is typing". Although such features may be primarily intended for supporting interpersonal awareness, monitoring the presence of these cues can allow for some minor reflection about effort. Here we consider how designs might embed cues about effort in the recipient's experience of reading a message. Our intention is to provoke deeper reflection about the meaning and value of a sender's effort, as invested in the process of composing a message. A second aim is to identify issues that might temper this as a design opportunity and which would therefore need to be taken into account within future designs.

\section{DESIGNS FOR REFLECTION OVER EFFORT}

Our study explores three plausible approaches for encouraging reflection about effort in text-based messages. The designs we consider are ReWriting, Message Meters, and Message Miner. Each design embodies a different approach to addressing the same goal, i.e. that of provoking reflection about effort by giving the recipient information about the actions of the sender.

The designs we consider are envisaged as augmentations to chat systems [9] and were instantiated as low-fidelity interface prototypes, with functionality sufficient to convey key elements of the interaction. We chose this approach because initial prototypes can elicit user feedback that is capable of guiding the development of more refined products [e.g. 17, 41]. As such, it is not our aim to show that our designs are effective solutions for revealing effort; rather, they are intended as prompts that illuminate different aspects of the design problem [35] and which are sufficient to identify concepts that are important for people in close personal relationships [23, 36].

Our designs were derived from group ideation sessions in which the members of our research team generated ideas for technologies to reveal effort. The ideation in these sessions was guided by previous work on effortful communication $[23,24,31]$. The sessions resulted in a range of possible designs, and our study focuses on three of these. For the present work, we consider the designs as applied to textbased communication in the style of IM and email. This is because text is highly mutable and can give rise to significant effort in composition [32, 50], making it an ideal medium to explore effort. Moreover, text-based chat remains a primary outlet for the maintenance of relationships [18, 23, 34], allowing our designs to be envisaged in relation to contemporary technologies.

Since our study is focused on text-based messaging, we imagined that participants would struggle to engage with the designs if they were not supplemented by realistic content. We therefore presented each design to participants in the context of a mocked-up messaging application. We also created a set of messages for participants to read when using the designs. All participants saw the same set of messages, and each design was accompanied by a uniquely composed message (see below). While it would be preferable to use real messages from our participants, we opted not to do this due to concerns for privacy and practicality. Additionally, previous work suggests that people are able to apply initial design ideas to the context of their own relationships, even if they do not use them with real life partners [17].

\section{Design 1: ReWriting}

Our first design embodies the idea of providing direct insight into the actions taken by a message sender. This is done by showing complete information about the sender's procedural effort, as captured by their on-screen actions. In ReWriting, this is done by showing a retrospective replay of the sender's behaviour, i.e. a screen recording that shows procedural operations including mouse movements and typing of text 


\begin{tabular}{|c|c|c|c|}
\hline $\begin{array}{l}\text { Hey, } \\
\text { How are you doing? I need to say sorry } \\
\text { for the delay in my response, I hope you } \\
\text { didn't miss me too much? :) } \\
\text { I wanted to write and tell you about our } \\
\text { tip to the zoo last week I know you've } \\
\text { been wanting to go tor a while but I'm } \\
\text { atraid I have to spoil it - it was really good! } \\
\text { Can we chat about Dad's Christmas } \\
\text { present? I was thinking that it's really } \\
\text { important to continue our litte tradition of } \\
\text { buying him a joint gift. Any ideas what we } \\
\text { can get? } \\
\text { See you soon } \\
\text { Sam xxx }\end{array}$ & $\begin{array}{l}\text { Hey, } \\
\text { I wanted to wite and tell you about our } \\
\text { tip to the zoo last week. Inow you've } \\
\text { been wanting to go for a while but I'm } \\
\text { atraid I have to spoil it - it was really good! }\end{array}$ & $\begin{array}{l}\text { Hey, } \\
\text { How are you doing? I need to say sorry } \\
\text { for the delay in my response I hope you } \\
\text { didn't miss me too much? :) } \\
\text { I wanted to wite and tell you about our } \\
\text { tip to the zoo last week. I know you've } \\
\text { been wanting to go for a while but I'm } \\
\text { atraid I have to spoil it - it was really good! } \\
\text { Can we chat about Dad's Christmas } \\
\text { present? }\end{array}$ & $\begin{array}{l}\text { Hey, } \\
\text { How are you doing? I need to say sorry } \\
\text { for the delay in my response, I hope you } \\
\text { didn't miss me too much? :) } \\
\text { I wanted to write and tell you about our } \\
\text { tip to the zoo last week. I know you've } \\
\text { been wanting to go for a while but I'm } \\
\text { atraid I have to spoil it - it was really good! } \\
\text { Can we chat about Dad's Christmas } \\
\text { present? I was thinking that it's really } \\
\text { important to continue our litte tradition of } \\
\text { buying him a joint gift. Any ideas what we } \\
\text { can get? } \\
\text { See you soon } \\
\text { Sam xxx }\end{array}$ \\
\hline
\end{tabular}

Figure 1: The ReWriting design. Pressing the Play button allows participants to watch a replay of the message as it was composed by the sender, providing insights into editing behaviours as they unfolded in real time.

(see Figure 1). The idea is for the replay to run from the moment the sender begins to author their message. The replay then ends when they decide to press send.

After the message is delivered, the recipient can view a replay to understand how the sender composed the message. We were interested to see how participants might react to this level of detail about composition activity, and what it might entail for their acceptance of revealing sender effort.

For the purposes of our study, ReWriting was instantiated using a video file created by the authors. Participants viewed a screen recording of a single message being written by a fictional person named Sam. The replay lasted five minutes and showed Sam writing a message containing three paragraphs. The video showed Sam authoring the message and engaging in various edits, including typo corrections, sentence deletions, and the rearranging of passages. Participants were allowed to watch one minute's worth of footage before being asked to comment on the design. The replay continued in the background and remained visible while the participant continued to provide reflective feedback.

\section{Design 2: Message Meters}

Our second design is intended to provide a partial view of the sender's actions through the idea of quantifying actions in a sender's editing behaviour. In Message Meters (Figure 2 ), this is instantiated by showing measures of process that speak to procedural actions-such as the number of words typed and edits made-but without giving full insight into the sender's behaviour. This design thus differs to ReWriting in that the recipient does not see the edits taking place; they simply see the 'effort' captured by the meters as an augmentation to a received message. We reasoned that objective data furnished by a meter can allow for inferences about effort, but since meters provide only a partial account of a person's composition behaviour, subjective interpretation is required in terms of understanding what the data means [26]. We wanted to explore the meanings participants might ascribe to a meter and the limitations they might identify when reflecting on the effort of a message sender.

Participants in our study each viewed two different Message Meters. These meters were implemented as simple mockups using graphics editing software. Participants read a message from 'George' which talked about Christmas and how it would soon be time to buy gifts and put up the festive decorations. While reading the message, participants were able to view two meters that showed information about George's composition. The first was a comparison meter that showed a measure of "how the message compared to usual". The meter's reading was arbitrarily positioned above the midpoint of the scale, indicating that the writer invested "a little more effort than normal”. This reading was ambiguous in that it did not specify whether this was the normal amount between the sender and the recipient, or the normal amount between the sender and other people. This allowed us to elicit possible interpretations from participants.

The second meter was a statistics meter that showed a range of typographical metrics, some of which truthfully reflected the properties of the message shown on screen, e.g. word count. Other metrics hinted at changes the sender had made during composition, e.g. words changed and words deleted. This meter served as an additional prompt for stimulating reflection on the sender's behaviour in relation to meaningful effort.

\section{Design 3: Message Miner}

Our third design omits details about sender action and conveys effort through the idea of abstract mapping between the sender and recipient. In Message Miner (Figure 3), this idea is instantiated through the metaphor of digging for treasure. Users are required to move a miner character by pressing keyboard buttons until the miner reaches the received message. Each keypress causes the miner to 'dig' further towards the message. The amount of mining required by the recipient (i.e. the number of pixels travelled per keypress) is proportional to the total effort invested by the sender, where more effort 

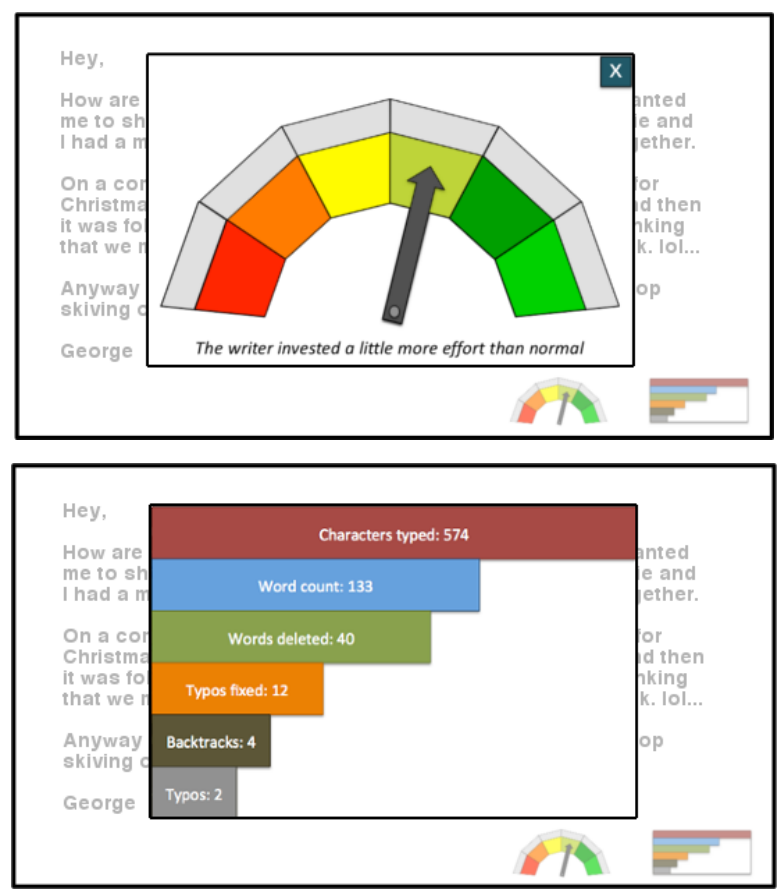

Figure 2: The Message Meters design, showing the comparison meter (top) and the statistics meter (bottom). Participants were able to reveal or hide the meters while reading the message shown in the background.

in composition equates to a greater number of miner moves. However, the system provides no information about what kind of effort the keypresses represent. The design therefore probes the idea of establishing an abstract mapping between sender and recipient effort, transforming the task of message retrieval into an opportunity to reflect on the sender's investment (i.e. by thinking about what the keypresses mean). We wanted to probe the inferences participants might form on the basis of Message Miner alongside their acceptance of a design that requires effort to access messages.

Message Miner was implemented using Snap! ${ }^{1}$, a variant of the Scratch programming language. Participants used Message Miner to access three messages from a friend named Casey, who was writing to divulge details of a recent holiday. Each use of the design required more effort to access the message, and the message retrieved was correspondingly longer and more detailed. Specifically, the first use required 60 keypresses to reach the message; the second required 120; and the third needed 300. This range was selected to mirror the sequentially escalating word count of the messages retrieved by the miner, and because we were interested in how participants would reflect on the meaning of the mining task in relation to the sender's effort investment.

\footnotetext{
${ }^{1}$ http://byob.berkeley.edu/
}

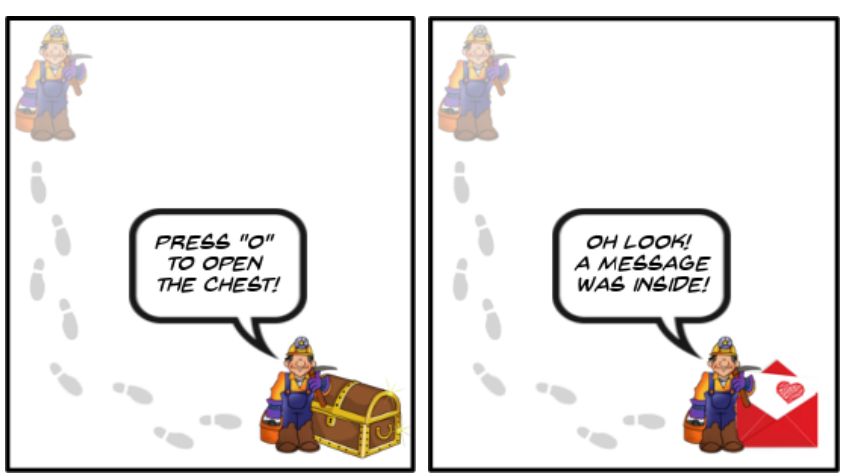

Figure 3: The Message Miner design. Participants pressed the keyboard to move the miner to the treasure chest, giving access to a message. Greater effort by the sender equated to higher number of presses by the recipient.

\section{METHOD}

We designed a study to gather users' reactions to our three designs, allowing us to shed light on the general concept of provoking reflection about effort. The study was created in accordance with a local ethics checklist at the University of Bath. Each of the designs was pilot tested and was found to induce no discomfort. However, we note that Message Miner required participants to invest physical effort in the form of repeated keypresses. Our briefing script included a warning about this, giving participants an opportunity to raise concerns in advance. Furthermore, we allowed participants the right to refuse to use any of the designs, and we made it clear that participants could stop using a design if they experienced any discomfort. None of the participants opted to do this.

Twelve adults ( 9 females, 3 males) participated in the study. All were recruited through an advertisement posted on an online noticeboard at the University of Bath. The advertisement stated that we were looking for people "to participate in a study of novel messaging systems". Participants' ages ranged from $19-32(M=23.4$ years, $S D=4.9)$. Four people were from the United Kingdom and three were from Malaysia. The remaining five came from Poland, India, Turkey, Taiwan, and Nepal (one person from each country).

All participants reported using text-based IM technologies such as Whatsapp, Facebook Messenger or WeChat to maintain their relationships. The fact that our sample is comprised of young and tech-savvy individuals is useful as it means that our designs were interpreted by people who were well-placed to give feedback about the potential for new features in IM apps, and who were therefore able to assess the perceived merit of conveying a sender's effort. 


\section{Procedure}

We employed an interview strategy in which participants were invited to our laboratory and were asked to reflect on their thoughts and feelings as they engaged in use of each design. This procedure is an accepted technique for eliciting user feedback and has been used extensively in previous studies of low-fidelity prototypes [e.g. 17, 35].

Interviews were semi-structured and lasted between 58110 minutes ( $M=80$ minutes). Each was one-to-one between the first author and participant. Sessions began with collection of informed consent. The researcher then read aloud a briefing script explaining that the research was about communication devices for close personal relationships. Participants were asked about the technologies they use to communicate with close contacts. This enabled us to probe how each of our designs might be applied to the systems that participants currently used to maintain their relationships.

Next, the designs were introduced in a randomised order for each participant. Each design was shown on a laptop that was placed on a table in front of the seated participant. Participants were asked about their initial impressions towards the idea and what they thought about the underlying concept. They then interacted with the interface prototype and gave further reflective feedback. Our focus was on participants' initial impressions of each design; how their thoughts changed through actual use; the reflections they made about the sender's effort; and the issues that would affect their acceptance of the designs in practice. We also asked participants to consider both the sender and recipient experience, meaning that our responses accounted for both perspectives.

Sessions concluded by asking participants to compare and discuss the designs as a way of probing their general attitude to the idea of making communication effort visible. Sessions ended with a short debrief, during which time participants were thanked and paid $£ 10$ for their time.

\section{Analysis}

The interviews were audio recorded and transcribed by the first author. Transcripts were subjected to an inductive thematic analysis [6] in which the first and second authors independently read the data and performed open coding to identify initial concepts. These concepts were then discussed by the authors and grouped into major themes that encapsulated (1) reflections on the value and meaning of sender effort, as revealed by the specifics of each design, and (2) connections between participants' experiences that spoke to broader issues stemming from the revelation of effort. The latter of these categories was separated into three sub-themes, each of which encapsulated a salient issue that emerged in response to reflections about sender effort. All themes were then reapplied to the data in a round of deductive coding, performed by the first and second authors independently. This process allowed themes to be checked for consistency, heterogeneity and logical coherence [6]. In the next section, we illustrate the outcomes of our analysis using quotes that identify participants by number and the design they were reacting to at the time.

\section{REFLECTIONS ON THE VALUE OF REVEALED EFFORT}

The designs provoked a range of positive and negative opinions about the impact of revealing effort in personal communication. Participants were able to reflect on how the concepts could map to their current relationships and how features within the designs would alter different aspects of their communication behaviour.

At a broad level, participants indicated that they would find value in seeing information about the effort of a close relational partner, irrespective of how that effort was conveyed. People especially valued the idea of gaining insight into actions that they believed were genuine and which would tell them something about the sender's motivations. Participants actively reflected on the meaning of the information conveyed by each design, and interpreted this in relation to the thoughts, intentions and attitudes of the sender.

For example, when reacting to ReWriting, participant 6 felt that "I can see why it is good, because someone you care about, you can see when they phrase stuff... and you can see how sincere they are, their intentions and everything”. The ability to reflect on the sender's actions was envisaged as an opportunity for empathy and to learn more about their personality: "It would make you feel a bit closer to the person who's writing it, because you can actually imagine them, sat there writing it" [P3, ReWriting]. "It just shows what kind of person he is. And sometimes if I know him, and I will be like... it's reassuring that guy is that kind of person" [P6, Meters].

Participants also commented on information that allowed them to reflect on the investment of time and care in message composition. For example, reviewing the Message Meter was enough for participant 7 to claim that "Words changed shows how many times they went back and changed something, again it shows a little bit of effort" [P7, Meters]. The ability to acknowledge this kind of effort was valued as a way of understanding the sender's perceived care towards the recipient: "I don't really care what you say, if you say it in ten words or fifty words, but if you take your time to go back and change things, I feel like that shows you care" [P4, Meters].

One area of interest mentioned by four participants was in using the designs to reflect over mental effort, i.e. what the sender was thinking about when composing a message and how this might demonstrate meaningful investment. Participants reflected on mental effort in terms of the time spent by 
the sender on the message and the apparent thoughtfulness (or lack thereof) in creating each message. The ReWriting design, which permitted direct insight into the sender's action, was cited as especially informative in this regard. One person described watching the replay as "a moment when I am thinking what they are thinking, in a way. It makes me feel closer to the sender" [P1, ReWriting].

Participants likewise commented on features that they believed were not useful for understanding mental effort and thoughtfulness. For example, elements of Message Meter were seen as "just like a word count, it's not very representative of the thought behind it" [P3, Meters]. Participants also struggled to interpret the meaning of Message Miner's abstract mapping in terms of the message's properties: "It seems to be that the number of times you have to tap the thing corresponds to the length of the message. Not to the actual importance of the message" [P9, Miner].

\section{ISSUES IN REVEALING EFFORT}

Participants' comments drew our attention to three issues that related to viewing and interpreting a sender's effort. These issues cut across the designs, and each design helped to illuminate the issues in different ways.

\section{Desiring Authenticity in Effortful Action}

In reacting to the information that was provided by the designs, participants reflected on two kinds of authenticity that they sought to understand from the information provided. The first related to motivational authenticity, where participants wanted to understand whether the invested effort was committed under the sender's own volition or whether it was invested 'for the sake of it'. This has parallels with Kelly et al.'s concept of discretionary effort [24], which they describe as effort that is invested willfully by a sender and which is not prompted by a messaging system.

These concerns were raised in relation to questions around whether the designs portrayed meaningful effort. For example, when reacting to the Message Meters, one person described how "the word count itself, I don't say is always a representation of effort because people can just write a lot of waffle, as opposed to actually saying what they mean" [P5, Meters]. Participants also envisaged that senders might alter their behaviour to make it look as though greater effort had been put into a message. Such cases would result in effort that was not genuine: "Having this meter would sometimes be quite bullshitted. You could actually cheat the system if you do more than usual" [P2, Meters]. These statements demonstrate an interest in the faithfulness of the sender's behaviour, given the introduction of a mediating technology that would show their actions to the recipient.

A second concern was for representational authenticity, i.e. whether the design provided a fair and truthful reflection of the sender's investment. For two people this was a matter of trust: "I would need to know more about the system, what it is taking into account" [P1, Miner]. "I don't know the factors involved, I don't know how they quantified them, I don't know what company is behind it, they might have some sort of bias..." [P10, Meters]. Participants cast doubt as to the potential for systems to give a true reflection of sender behaviour and were sometimes unsure what the information really meant: "It's hard for me to imagine the person has put that much effort but maybe I don't have a good point of reference for how much effort it is." [P1, Miner].

However, an interesting consequence of these concerns was that participants saw the potential to playfully appropriate the designs. Three individuals anticipated that they could leverage the 'unreliability' of the prototypes to embed 'hidden effort' in the composition of a message. This would be intended for later discovery by the recipient: "You can do really cool funny things like if the guy actually knows this is going on, the sender, you could like type halfway, and then type a long funny joke. And just rub it off, like inside joke, a message within a message." [P2, ReWriting]. This was also seen as a way of deliberately increasing the recipient's effort as a way of playful goading: "I can see a problem with this, if a guy puts a lot of space into it, just da da da [space bar], and then you gotta press it for a long time, and they come up with empty text! So you could troll somebody with that" [P2, Miner]. Such effort may not relate to the message's final text but would become an authentically expressed form of effort through the playful embedding of a 'message within a message'. This might be valued given the significance of play for close relationships [4] and emphasizes the potential for play to be mediated by technology [47].

\section{Controlling Reciprocal and Self-Disclosure}

Each of our designs provided a different level of information about the actions of a message sender: ReWriting allowed detailed insight, whereas the Message Miner offered an abstract mapping. In reflecting on this aspect, participants recognised that the act of creating a message is very much a performance, and that the received message may be different to what the sender initially planned. As articulated by Goffman [14], the act of presenting oneself to an audience (in this case, a message recipient) involves revealing certain pieces of information while withholding others. The basis for revealing information is frequently the audience with whom one is interacting; an adult may, for example, present themselves differently at home compared to their workplace [14].

While the three designs were broadly valued for allowing appreciation of effort, participants envisaged problems in retaining control over self-disclosures. This was particularly the case for the ReWriting design, which gave direct insight into the sender's on-screen behaviour. As one participant 
explained, "I find it not really fair because that's not what the person wants you to see" [P1, ReWriting]. Participants thus recognised that mediated communication permits an author to put forward statements and later rescind them before a message is sent [50]. Gaining insight into this was seen as problematic and potentially distracting from the received message: "I tend to write stuff out and then delete it, and then rewrite other things. I mean the point is you haven't sent it so that you don't want them to read it. Whereas if you had this, they would read it" [P3, ReWriting].

The designs also made participants reflect on privacy concerns in messaging, particularly in terms of detail that is surrendered about the sender's behaviour: "I feel like it's a private thing, you know. It's people looking into your private life a bit too much... I don't want people seeing my process of writing emails" [P10, ReWriting]. The ReWriting design was provocative in this regard, with six people expressing that the level of detail afforded by the system made them feel as though they were 'spying' on the sender: "I feel like it could cause over-analysing. People are already obsessing over the blue ticks they see in Whatsapp. And this would cause a lot more personal drama" [P4, ReWriting].

Although many participants did not always want to reveal their own behaviour, it was interesting that they were often keen to see others' actions. That is, participants wanted to see others' efforts but were not always willing to engage in reciprocal disclosure: "I think it's one of those things that I would like to be able to see what other people have written, but I wouldn't want them to be able to see what I've written. Because then they'd see stuff that you didn't actually intend for them to see." [P3, ReWriting]. Only one participant expressed the opposite view in that she would be willing to disclose her own work but did not want to see other people's due to fear of discovering their intentions towards her: "I think for me I will let other people see me, but to be honest, I might not use on other people. I guess I am too afraid to know the truth, something like that" [P11, ReWriting]. This demonstrates the potential for designs to reveal meaningful effort while also exposing a lack of such effort within relationships.

Some participants stated that they would change their behaviour in light of features that revealed effort. This links back to the notion of authenticity-if users alter their communication practices in response to the presence of the effortrevealing features, then their resultant actions are no longer their 'authentic' selves: 'I think it would probably make you think about what you're writing a lot more. And you would probably feel motivated to put a lot more effort in than you might've intended to at the beginning." [P5, ReWriting].

The ability to gain information about effort also seemed to impact the people with whom participants wanted to use the designs. Some participants thought that the designs would be useful to show they were putting in the effort to get to know someone: "I think it could be when you want to get closer to someone but you're not close yet, it can be like a way to see how they write" [P6, Message Meters]. "I think this would be really interesting if I was using it with someone that I'm newly dating." [P7, ReWriting]. This suggests that inviting reflection about effort might be useful for escalating relationships [42] as well as maintaining established connections.

\section{Costs in Acknowledging Effort}

Our final theme encapsulates participants' views about the costs required to view, interpret, and respond to sender effort. Any attempt to convey sender effort inevitably introduces new costs into the interaction, whether in the use of the system or in terms of requiring additional work to acknowledge invested effort. We identified that participants recognised this work and interpreted it in two ways.

First, informants questioned the costs for message recipients to discern sender effort, given the mechanisms by which effort was revealed. While some initial reflections exemplified the value of learning about a partner's actions, these views were tempered by the effort required to do this. Participants desired some balance between a meaningful representation and the effort required to make sense of it: "I don't want to go through extra effort if I don't see any added value. If I were to learn more because paying makes you remember better, or pay more attention, if there was anything of that kind then maybe" [P1, Miner].

The Message Meters design, while recognized as an imperfect solution for reflecting on effort, was valued for being straightforward to interpret: "I would use this with people like my family. I think it's quite easy to sort of see without having to think about it too much" [P3, Meters]. In cases where significant effort was required to interpret the information, participants stated that they would prefer to put work into other tasks: "I would rather invest the time in actually responding to that person in the same way, exactly like they've invested time into responding to me" [P12, Miner].

Beyond costs in interpreting sender effort, participants perceived that the designs introduced new costs in the experience of accessing messages. Additional effort in checking messages was sometimes seen as outweighing the benefits ("It's a lot of effort just to get a line asking, do you want to meet up?" [P5, Miner]) and was only tolerable when the value of the acquired message outweighed the cost of access: "I think the experience of reading this mail is nice, so I think tapping was worth it" [P7, Miner]. Participants envisaged feeling more inclined to reveal effort if it was optional: "this is less practical if it was something you had to watch." [P3, ReWriting].

The cost of accessing messages also seemed to affect participants' appetite for reflecting on sender effort. Six people imagined that they would become bored, particularly by 
ReWriting, which required a long time to watch the message being written. Two people saw this as "boring and laborious for the reader" [P2, ReWriting], or "tedious... Why do I want to watch them retype it? I haven't got time” [P12, ReWriting]. Likewise, the Message Miner would "be quite fun the first few times, but after a lot of messages come through, it would just be, oh another one" [P2, Miner].

However, these instances helped participants to reflect on when they would like to reflect on invested effort. Three participants stated that, rather than looking at the effort of every single message, they would prefer to see a sender's effort on special occasions. This suggests that revealed effort could complement especially meaningful messages, with the sender's work becoming part of the message's rhetorical charm: "maybe if it was an important moment, such as your friend is getting married and she's announcing the news to you, it would be quite nice to watch them write it as a nice memory for yourself and how they feel about it" [P5, ReWriting].

Costs in access were generally seen as negative, but some participants did reflect on how these costs could benefit their messaging practices. One person thought that effort in access might encourage the dedication of time to the messaging experience: "You're not going to put in a lot of effort while you're standing in a public place, where you're not really gonna read the letter. You'd probably wait until you're at home, sit and put the effort in and then actually properly read the letter" [P3, Miner]. Another thought that it would help him to focus on important messages: "I always open up Whatsapp every time and just check, whatever irrelevant messages, like sometimes I'm in a group chat, and it's like not regarding me but I'll still look at it. So... in a way, waste my time a bit. If we have this feature I would probably think twice whether to consider which message I want to read" [P6, Miner].

\section{DISCUSSION AND IMPLICATIONS}

Our aim in this study was to explore how messaging systems might provide information about a sender's effort as a way of fostering appreciation by message recipients.

\section{Promoting Reflection and Revealing Hidden Effort}

Our first main finding is that the general concept of revealing effort appears to have value to people, provided that it allows them to identify meaningful work conducted during the composition of messages. Participants in our study were particularly interested in cues that allowed them to recognise the investment of time and care [24], pointing to the potential for revealed effort to stimulate new kinds of shared understandings about a partner's intentions [5]. Participants also suggested that the designs were capable of creating feelings of empathy and closeness, both of which are important for mediating close relationships [20]. This speaks to the potential value of supporting reflection on effort and its contribution to close personal communication. As a general implication, designers might consider allowing senders and recipients to reveal aspects of their composition behaviour as a way of conveying care towards the recipient. This might also provide support for appropriation and play, as suggested by participants in our study.

A second finding was that participants valued insight into a sender's thought processes, with participants often interpreting each design in terms of how it portrayed thoughtfulness and mental effort. One explanation for this is that mental effort invested into messages is likely to be difficult for the recipient to determine. As such, information about a sender's mental effort-particularly if it evidences some degree of thoughtfulness-is likely to be valued because it is meaningful and yet may not be entirely evident in what is received. (For example, one can imagine sending a message that is very short but which required a great deal of thought to choose the most appropriate words.)

As a design implication, future systems might therefore consider ways of augmenting messages with information about physiological state as a way of creatively stimulating appreciation of mental effort [29]. Previous work has shown that signals such as heart rate [21] can help to support awareness and empathy-we suggest that cognitive information could provide a novel resource for conveying a sense of empathy towards the recipient, while providing cues about effort in the process of composition.

\section{Negotiating the Consequences of Revealed Effort}

Our research has also provided an understanding of issues that temper the potential for effort to be revealed. We found that users desire authenticity of action, controlled disclosure and low costs when reflecting on effort in communication.

Given users' reactions to our prompts, we suggest that each of these issues is a property of the interaction design that can become more or less salient depending on the means by which effort is revealed. For example, the need to control self-disclosure was most salient in ReWriting, which gave great insight into the composition of messages, but this need was less of an issue in Message Miner. On the other hand, Message Miner drew participants' attention to the costs associated with interpreting effort, whereas this was less salient for the Message Meters. And while the Message Meters were considered easy to interpret, they were seen as less useful for understanding authenticity than ReWriting.

This leads us to suggest that the issues we have identified should not be seen as 'solvable' in the sense of simple design fixes, but are rather parameters that must be carefully negotiated and balanced by the designer, given the situation at hand. In practical terms, this might mean placing greater emphasis on one parameter over another when designing for a particular relationship. People who are already close 
to each other may be comfortable with the idea of intimate self-disclosures [5] whereas weak-tie relations may be disrupted by the unintended revealing of personal information. Similarly, people may be hesitant to place effortful costs on relatives who find it hard to use technology [24], but may still wish to make use of effort-revealing functionality that supports a sense of care.

An alternative approach would be to give users control over the negotiation of each parameter. For example, a future version of the ReWriting idea might allow senders to control their self-disclosure by altering the fidelity of the revealed text, e.g. with a slider that allows for blurring of the words. This would provide control over what is shared, while still allowing for evidence that something was done. Users might also be allowed to subtract segments of the replay that they do not wish to share, or could be given ways to draw attention to particular parts as a way of demonstrating authenticity. The replay could also be played at faster speed to lower the time cost to the recipient. The facility to convey effort might also be made as entirely optional, and something to be shared at the sender's discretion.

However, our study findings could also be interpreted as demonstrating that there is sufficient motivation to rule out the use of effort-revealing features in communication. For example, some participants suggested that reflecting on effort would be unsuitable for everyday conversation and would 'get in the way' of what they wanted to achieve. Others thought that the revelation of effort might be best left for special moments that were already meaningful, such as when divulging important moments or significant life events. This suggests that effort-revealing features could have a role to play, not as accompaniments to everyday messaging, but rather as amplifiers that further enhance the reading of messages that already involve greater work than usual. In this way, the gradual revelation of effort could contribute to experiences of deep interpersonal sharing between people who care about one another [5]. We imagine that revealing the process of message composition would lend itself to very personal experiences such as the celebration of a major life event or even a declaration of love.

\section{Limitations and Future Work}

One limitation of our study is that participants' responses to the designs were disconnected from their actual relationships. It is possible that real-world use might uncover a more complex set of values than those captured in our study. A second limitation is that, while our participants were culturally diverse, they were relatively young and tech-savvy. This made them capable of commenting on the designs in relation to their own lives, but it may be the case that other groups (such as older adults [28]) have different values that would condition their acceptance of designs that reveal and provoke reflection about effort.

Finally, it is important to recognise that relationships are enacted over multiple communication episodes. We were unable to account for this in our laboratory study. Rather than representing effort as part of a fleeting experience, a different approach would be to explore aggregate representations in the form of conversation histories or other features that show effort accruing over time. The perceived need to invest effort and reciprocate in kind is likely to be conditioned by a history of previous conversations between the participants in an exchange. We imagine future approaches to effortsensitive design extending to corpora of caring messages, not only the turn-by-turn mechanisms through which they are created. This in turn speaks to the potential for our study to stimulate new design thinking on the subject of how to reveal and represent effort in caring relationships.

\section{CONCLUSION}

In this paper we have focused on effort in the composition of written messages as a central component of caring communication. We have addressed this matter as a design problem, and we have explored a set of designs that represent plausible solutions. These solutions not only exposed the value that might be gained from revealing effort, but also supported a series of considerations that can inform future attempts to represent effort in communication systems. To conclude, we argue that providing visible evidence of effort may offer a positive contribution to the maintenance of relationships. This is, however, premised on the ability of designers to instantiate the revelation of effort in systems that also respect fundamental qualities of relational action, and which provide conversation partners with the ability to recognise, and sometimes withhold, aspects of composition that contribute to the maintenance of caring relationships.

\section{ACKNOWLEDGMENTS}

This work is funded by the Leverhulme Trust under grant number PRG-2013-269. We thank a number of anonymous reviewers for suggestions that improved this paper.

\section{REFERENCES}

[1] Paul M. Aoki and Allison Woodruff. 2005. Making Space for Stories: Ambiguity in the Design of Personal Communication Systems. In Proceedings of the SIGCHI Conference on Human Factors in Computing Systems (CHI '05). ACM, New York, NY, USA, 181-190. https://doi. org/10.1145/1054972.1054998

[2] Hanif Baharin and Salman Khalidi. 2015. Fyro: A Symbolic-Based Phatic Technology. In Proceedings of the Annual Meeting of the Australian Special Interest Group for Computer Human Interaction (OzCHI '15). ACM, New York, NY, USA, 304-308. https://doi.org/ 10.1145/2838739.2838795

[3] Eric P.S. Baumer, Vera Khovanskaya, Mark Matthews, Lindsay Reynolds, Victoria Schwanda Sosik, and Geri Gay. 2014. Reviewing 
Reflection: On the Use of Reflection in Interactive System Design. In Proceedings of the 2014 Conference on Designing Interactive Systems (DIS '14). ACM, New York, NY, USA, 93-102. https://doi.org/10.1145/ 2598510.2598598

[4] Leslie A Baxter. 1992. Forms and functions of intimate play in personal relationships. Human Communication Research 18, 3 (1992), 336-363.

[5] Stacy Branham and Steve Harrison. 2013. Designing for Collocated Couples. Springer London, London, 15-36. https://doi.org/10.1007/ 978-1-4471-4192-1_2

[6] Virginia Braun and Victoria Clarke. 2006. Using thematic analysis in psychology. Qualitative Research in Psychology 3, 2 (2006), 77-101.

[7] Moira Burke, Robert Kraut, and Cameron Marlow. 2011. Social Capital on Facebook: Differentiating Uses and Users. In Proceedings of the SIGCHI Conference on Human Factors in Computing Systems (CHI '11). ACM, New York, NY, USA, 571-580. https://doi.org/10.1145/1978942. 1979023

[8] Moira Burke and Robert E. Kraut. 2016. The Relationship between Facebook Use and Well-Being depends on Communication Type and Tie Strength. Journal of Computer-Mediated Communication 21, 4 (2016), 265-281. https://doi.org/10.1111/jcc4.12162

[9] Daniel Buschek, Mariam Hassib, and Florian Alt. 2018. Personal Mobile Messaging in Context: Chat Augmentations for Expressiveness and Awareness. ACM Trans. Comput.-Hum. Interact. 25, 4, Article 23 (Aug. 2018), 33 pages. https://doi.org/10.1145/3201404

[10] Marianne Dainton and Brooks Aylor. 2002. Routine and strategic maintenance efforts: Behavioral patterns, variations associated with relational length, and the prediction of relational characteristics. Communication Monographs 69, 1 (2002), 52-66.

[11] Hilary Davis, Mikael B. Skov, Malthe Stougaard, and Frank Vetere. 2007. Virtual Box: Supporting mediated family intimacy through virtual and physical play. In Proceedings of the 19th Australasian Conference on Computer-Human Interaction: Entertaining User Interfaces (OZCHI '07). ACM, New York, NY, USA, 151-159. https://doi.org/10.1145/1324892. 1324920

[12] Kathryn Dindia and Daniel J Canary. 1993. Definitions and theoretical perspectives on maintaining relationships. fournal of Social and Personal Relationships 10, 2 (1993), 163-173.

[13] John Downs, Nicolas Villar, James Scott, Siân Lindley, John Helmes, and Gavin Smyth. 2014. A Small Space for Playful Messaging in the Workplace: Designing and Deploying Picco. In Proceedings of the 2014 Conference on Designing Interactive Systems (DIS '14). ACM, New York, NY, USA, 285-294. https://doi.org/10.1145/2598510.2598511

[14] Erving Goffman. 1959. The Presentation of Self in Everyday Life. Penguin, London.

[15] Daniel Gooch and Leon Watts. 2011. A Design Framework for Mediated Personal Relationship Devices. In Proceedings of the 25th BCS Conference on Human-Computer Interaction (BCS-HCI '11). British Computer Society, Swinton, UK, UK, 237-242. http://dl.acm.org/ citation.cfm?id $=2305316.2305360$

[16] Daniel Gooch and Leon Watts. 2011. The Magic Sock Drawer Project. In CHI '11 Extended Abstracts on Human Factors in Computing Systems (CHI EA '11). ACM, New York, NY, USA, 243-252. https://doi.org/10. 1145/1979742.1979613

[17] Daniel Gooch and Leon Watts. 2012. YourGloves, hothands and hotmits: devices to hold hands at a distance. In Proceedings of the 25th Annual ACM Symposium on User Interface Software and Technology (UIST '12). ACM, New York, NY, USA, 157-166. https://doi.org/10. $1145 / 2380116.2380138$

[18] Rebecca E. Grinter and Margery A. Eldridge. 2001. y do tngrs luv 2 txt msg?. In Proceedings of 2001 European Conference on Computer Supported Cooperative Work. Springer, 219-238.

[19] Sandra G Hart and Lowell E Staveland. 1988. Development of NASATLX (Task Load Index): Results of empirical and theoretical research.
Advances in Psychology 52 (1988), 139-183.

[20] Marc Hassenzahl, Stephanie Heidecker, Kai Eckoldt, Sarah Diefenbach, and Uwe Hillmann. 2012. All You Need is Love: Current Strategies of Mediating Intimate Relationships Through Technology. ACM Transactions on Computer-Human Interaction 19, 4, Article 30 (Dec. 2012), 19 pages. https://doi.org/10.1145/2395131.2395137

[21] Mariam Hassib, Daniel Buschek, Paweł W. Wozniak, and Florian Alt. 2017. HeartChat: Heart Rate Augmented Mobile Chat to Support Empathy and Awareness. In Proceedings of the 2017 CHI Conference on Human Factors in Computing Systems (CHI '17). ACM, New York, NY, USA, 2239-2251. https://doi.org/10.1145/3025453.3025758

[22] Joseph 'Jofish' Kaye. 2006. I Just Clicked to Say I Love You: Rich Evaluations of Minimal Communication. In $\mathrm{CHI}$ '06 Extended Abstracts on Human Factors in Computing Systems (CHI EA '06). ACM, New York, NY, USA, 363-368. https://doi.org/10.1145/1125451.1125530

[23] Ryan Kelly, Daniel Gooch, , and Leon Watts. 2018. "It's More Like a Letter": An Exploration of Mediated Conversational Effort in Message Builder. Proc. ACM Hum.-Comput. Interact. 2, CSCW, Article 87 (Dec. 2018), 23 pages. https://doi.org/10.1145/32743565

[24] Ryan Kelly, Daniel Gooch, Bhagyashree Patil, and Leon Watts. 2017. Demanding by Design: Supporting Effortful Communication Practices in Close Personal Relationships. In Proceedings of the 2017 ACM Conference on Computer Supported Cooperative Work and Social Computing (CSCW '17). ACM, New York, NY, USA, 70-83. https: //doi.org/10.1145/2998181.2998184

[25] Ryan Kelly and Leon Watts. 2015. Characterising the inventive appropriation of emoji as relationally meaningful in mediated close personal relationships. Experiences of Technology Appropriation: Unanticipated Users, Usage, Circumstances, and Design (2015).

[26] Ryan Kelly, Leon Watts, and Stephen J. Payne. 2016. Can Visualization of Contributions Support Fairness in Collaboration?: Findings from Meters in an Online Game. In Proceedings of the 19th ACM Conference on Computer-Supported Cooperative Work \& Social Computing (CSCW '16). ACM, New York, NY, USA, 664-678. https://doi.org/10.1145/ 2818048.2819977

[27] Simon King and Jodi Forlizzi. 2007. Slow Messaging: Intimate Communication for Couples Living at a Distance. In Proceedings of the 2007 Conference on Designing Pleasurable Products and Interfaces (DPPI '07). ACM, New York, NY, USA, 451-454. https://doi.org/10. 1145/1314161.1314204

[28] Siân E. Lindley, Richard Harper, and Abigail Sellen. 2009. Desiring to Be in Touch in a Changing Communications Landscape: Attitudes of Older Adults. In Proceedings of the SIGCHI Conference on Human Factors in Computing Systems (CHI '09). ACM, New York, NY, USA, 1693-1702. https://doi.org/10.1145/1518701.1518962

[29] Fannie Liu, Laura Dabbish, and Geoff Kaufman. 2017. Can Biosignals Be Expressive?: How Visualizations Affect Impression Formation from Shared Brain Activity. Proc. ACM Hum.-Comput. Interact. 1, CSCW, Article 71 (Dec. 2017), 21 pages. https://doi.org/10.1145/3134706

[30] Daniel H Mansson and Scott A Myers. 2011. An initial examination of college students' expressions of affection through Facebook. Southern Communication fournal 76, 2 (2011), 155-168.

[31] Panos Markopoulos. 2009. A design framework for awareness systems. In Awareness Systems, Panos Markopoulos, Boris De Ruyter, and Wendy Mackay (Eds.). Springer, 49-72.

[32] Ann Matsuhashi. 1982. Explorations in the real-time production of written discourse. In What writers know: The language, process, and structure of written discourse, Martin Nystrand (Ed.). Academic Press New York, NY, 269-290.

[33] Bree McEwan. 2013. Sharing, caring, and surveilling: An actorpartner interdependence model examination of Facebook relational 
maintenance strategies. Cyberpsychology, Behavior, and Social Networking 16, 12 (2013), 863-869.

[34] Kenton P. O'Hara, Michael Massimi, Richard Harper, Simon Rubens, and Jessica Morris. 2014. Everyday Dwelling with WhatsApp. In Proceedings of the 17th ACM Conference on Computer Supported Cooperative Work \& Social Computing (CSCW'14). ACM, New York, NY, USA, 1131-1143. https://doi.org/10.1145/2531602.2531679

[35] James Pierce and Eric Paulos. 2014. Counterfunctional Things: Exploring Possibilities in Designing Digital Limitations. In Proceedings of the 2014 Conference on Designing Interactive Systems (DIS '14). ACM, New York, NY, USA, 375-384. https://doi.org/10.1145/2598510.2598522

[36] Martin Podlubny, John Rooksby, Mattias Rost, and Matthew Chalmers. 2017. Synchronous Text Messaging: A Field Trial of Curtains Messenger. Proc. ACM Hum.-Comput. Interact. 1, CSCW, Article 86 (Dec. 2017), 20 pages. https://doi.org/10.1145/3134721

[37] Yann Riche, Nathalie Henry Riche, Petra Isenberg, and Anastasia Bezerianos. 2010. Hard-to-use interfaces considered beneficial (some of the time). In CHI '10 Extended Abstracts on Human Factors in Computing Systems (CHI EA '10). 2705-2714. https://doi.org/10.1145/1753846. 1753855

[38] Yann Riche and Wendy Mackay. 2010. PeerCare: Supporting awareness of rhythms and routines for better aging in place. Computer Supported Cooperative Work (CSCW) 19, 1 (2010), 73-104.

[39] Natalia Romero, Panos Markopoulos, Joy Van Baren, Boris De Ruyter, Wijnand Ijsselsteijn, and Babak Farshchian. 2007. Connecting the family with awareness systems. Personal and Ubiquitous Computing 11, 4 (2007), 299-312.

[40] Irina Shklovski, Louise Barkhuus, Nis Bornoe, and Joseph 'Jofish' Kaye. 2015. Friendship Maintenance in the Digital Age: Applying a Relational Lens to Online Social Interaction. In Proceedings of the 18th ACM Conference on Computer Supported Cooperative Work \& Social Computing (CSCW'15). ACM, New York, NY, USA, 1477-1487. https://doi.org/10.1145/2675133.2675294

[41] Samarth Singhal, Carman Neustaedter, Yee Loong Ooi, Alissa N. Antle, and Brendan Matkin. 2017. Flex-N-Feel: The Design and Evaluation of Emotive Gloves for Couples to Support Touch Over Distance. In Proceedings of the 2017 ACM Conference on Computer Supported Cooperative Work and Social Computing (CSCW' 17). ACM, New York, NY, USA, 98-110. https://doi.org/10.1145/2998181.2998247

[42] Victoria Schwanda Sosik and Natalya N Bazarova. 2014. Relational maintenance on social network sites: How Facebook communication predicts relational escalation. Computers in Human Behavior 35 (2014),
$124-131$.

[43] Victoria Schwanda Sosik, Xuan Zhao, and Dan Cosley. 2012. See Friendship, Sort of: How Conversation and Digital Traces Might Support Reflection on Friendships. In Proceedings of the ACM 2012 Conference on Computer Supported Cooperative Work (CSCW'12). ACM, New York, NY, USA, 1145-1154. https://doi.org/10.1145/2145204. 2145374

[44] Rob Strong and Bill Gaver. 1996. Feather, scent and shaker: supporting simple intimacy. In Proceedings of the ACM Conference on ComputerSupported Cooperative Work, Vol. 96. 29-30.

[45] Anja Thieme, Jayne Wallace, James Thomas, Ko Le Chen, Nicole Krämer, and Patrick Olivier. 2011. Lovers' box: Designing for reflection within romantic relationships. International fournal of HumanComputer Studies 69, 5 (2011), 283-297.

[46] Stephanie T Tong and Joseph B Walther. 2011. Relational maintenance and CMC. Computer-mediated communication in personal relationships (2011), 98-118.

[47] Frank Vetere, Hilary Davis, Martin Gibbs, and Steve Howard. 2009. The Magic Box and Collage: Responding to the challenge of distributed intergenerational play. International fournal of Human-Computer Studies 67, 2 (2009), 165-178.

[48] Frank Vetere, Martin R. Gibbs, Jesper Kjeldskov, Steve Howard, Florian 'Floyd' Mueller, Sonja Pedell, Karen Mecoles, and Marcus Bunyan. 2005. Mediating intimacy: Designing technologies to support strong-tie relationships. In Proceedings of the SIGCHI Conference on Human Factors in Computing Systems (CHI '05). ACM, New York, NY, USA, 471-480. https://doi.org/10.1145/1054972.1055038

[49] Frank Vetere, Jeremy Smith, and Martin Gibbs. 2009. Phatic interactions: Being aware and feeling connected. In Awareness Systems, Panos Markopoulos, Boris De Ruyter, and Wendy Mackay (Eds.). Springer, 173-186.

[50] Joseph B. Walther. 1996. Computer-Mediated Communication: Impersonal, Interpersonal, and Hyperpersonal Interaction. Communication Research 23, 1 (1996), 3-43. https://doi.org/10.1177/ 009365096023001001

[51] Ferdinand Rudolf Hendrikus Zijlstra. 1993. Efficiency in work behaviour: A design approach for modern tools. PhD Thesis, TU Delft.

[52] John Zimmerman, Jodi Forlizzi, and Shelley Evenson. 2007. Research Through Design As a Method for Interaction Design Research in HCI. In Proceedings of the SIGCHI Conference on Human Factors in Computing Systems (CHI '07). ACM, New York, NY, USA, 493-502. https://doi. org $/ 10.1145 / 1240624.1240704$ 